\title{
Role of microRNAs in myogenesis and their effects on meat quality in pig - A review
}

\author{
Ambreen Iqbal', Jiang Ping ${ }^{1}$, Shaokat Ali ${ }^{1}$, Gao Zhen ${ }^{1}$, Liu Juan ${ }^{1}$, Jin Zi Kang ${ }^{1}$, \\ Pan Ziyi', Lu Huixian ${ }^{1}$, and Zhao Zhihui ${ }^{1, *}$
}

\begin{abstract}
* Corresponding Author: Zhao Zhihui Tel: +86-13560503527, Fax: +86-0759-2383248, E-mail: zhzhao@gdou.edu.cn
\end{abstract}

1 Department of Animal Breeding and Genetics, College of Coastal Agricultural Sciences, Guangdong Ocean University, Zhanjiang, Guangdong 524088, China

\section{ORCID}

Ambreen lqbal

https://orcid.org/0000-0002-2159-6697 Jiang Ping

https://orcid.org/0000-0001-7341-9070

Shaokat Ali

https://orcid.org/0000-0002-8349-0812

Gao Zhen

https://orcid.org/0000-0003-3278-8317 Liu Juan

https://orcid.org/0000-0002-8623-9738

Jin Zi Kang

https://orcid.org/0000-0002-6099-9296

Pan Ziyi

https://orcid.org/0000-0002-6013-2748

Lu Huixian

https://orcid.org/0000-0002-1154-0948

Zhao Zhihui

https://orcid.org/0000-0001-5907-0669

Submitted May 11, 2020; Revised Jul 2, 2020; Accepted Aug 16, 2020

\begin{abstract}
The demand for food is increasing day by day because of the increasing global population. Therefore, meat, the easiest and largely available source of protein, needs to be produced in large amounts with good quality. The pork industry is a significant shareholder in fulfilling the global meat demands. Notably, myogenesis- development of muscles during embryogenesis- is a complex mechanism which culminates in meat production. But the molecular mechanisms which govern the myogenesis are less known. The involvement of miRNAs in myogenesis and meat quality, which depends on factors such as myofiber composition and intramuscular fat contents which determine the meat color, flavor, juiciness, and water holding capacity, are being extrapolated to increase both the quantity and quality of pork. Various kinds of microRNAs (miRNAs), miR-1, miR-21, miR22, miR-27, miR-34, miR-127, miR-133, miR-143, miR-155, miR-199, miR-206, miR-208, miR-378, and miR-432 play important roles in pig skeletal muscle development. Further, the quality of meat also depends upon myofiber which is developed through the expression of different kinds of miRNAs at different stages. This review will focus on the mechanism of myogenesis, the role of miRNAs in myogenesis, and meat quality with a focus on the pig.
\end{abstract}

Keywords: microRNA; Myogenesis; Meat Quality; Pig

\section{INTRODUCTION}

The world's population has increased very rapidly in recent years. According to an estimate, the world's population in 1915 was approximately 1.8 billion. A recent survey by the United Nations (UN) estimated the world's population at 7.7 billion in 2019 will reach 9.7 billion by 2050 [1]. Over the years, the dietary habit of most people has changed owing to increase in population and changes in economy, especially in developing countries. This accounts for a high increase in demand for animal meat and protein. To meet the ever-increasing food demand requires more research for improving the existing food production system. The development of skeletal muscle is a complicated process comprised of embryonic myogenesis to postnatal muscle growth. The postpartum muscle growth in swine is dependent on the total number of myofibers which are generated in two waves before birth. Pig myogenesis occurs in two phases, the first phase includes the formation of primary myofibers from 35 to 55 days post coitus (dpc), followed by the formation of secondary myofibers around each primary myofiber between 50 and $90 \mathrm{dpc}$ [2]. Postpartum muscle growth is generally considered from birth to 60 days. Postnatal muscle growth mostly includes the conversion from slow-oxidative to fast glycolytic fiber types [3].

Meat quality is an important commercial trait in domestic animals, which is mainly estimated by intermuscular fat (IMF), $\mathrm{pH}$ value, tenderness, flavor substance, and water holding 
capacity. Further, meat quality is significantly affected by myofibers composition [4]. Quality of pork is mainly based on different kinds of myofibers and different contents of IMF present in different swine breeds. The pork industry mainly focuses on enhancing the muscle mass and development rate [5]. This goal achieved in various breeds of swine through genetic selection and cross-breeding [6]. Through these tactics, the Landrace swine breed has been developed, which has high body weight, rapid growth ability, and high lean meat percentage [7]. Despite Landrace, some local breeds have less weight and a slow growth rate, but these local breeds have high IMF content that affects the flavor of meat [8].

MicroRNAs are short (approximately 22 to 25 nucleotide), non-coding, single-stranded RNA molecules that are responsible for controlling gene expression through translational degradation, repression, and deadenylation of target mRNA. Studies present strong evidence that miRNAs play important roles in porcine skeletal muscle development [9-18]. The most important miRNA in myogenesis is miR-133a [19], which plays regulatory roles in muscle tissues [20-22]. Both miR-1 and miR-133 have multiple functions in myogenesis primarily, they are responsible for skeletal muscle development, and secondarily, they also act as myocyte enhancers [20]. Due to the advancement in sequencing technologies the numbers of miRNA discovered increased day by day [23]. Different type of miRNAs found to play regulatory roles in pig skeletal muscle development includes miR-1, miR-21, miR22, miR-27, miR34, miR-127, miR-133, miR-143, miR-155, miR-199, miR-206, miR-208, miR-378, and miR-432 [12,14,15,17,20,23-26]. Here, we will discuss the regulatory roles of different miRNAs in myogenesis and meat quality regulation in pigs.

\section{PRINCIPLES OF MYOGENESIS AND POSTNATAL MUSCLE GROWTH}

Prenatal swine myogenesis depends on the number of factors including nutrient accessibility, hormones, and growth factors that influence the changes in metabolism at the transcriptional and translational level of regulatory genes. These factors, linked with the myogenic regulatory factors, play a significant role in controlling muscle-specific gene expression [27]. Skeletal muscle development in pigs occurs in two phases, the first phase occurs from 35 to $55 \mathrm{dpc}$ in which the primary myofibers are formed and the formation of secondary myofibers around each primary myofiber occurs between 50 and $90 \mathrm{dpc}[2,28]$. In prenatal development of muscles, the content of fibers depends on the propagation and apoptosis of stem cell differentiation and the conjoining of myoblasts accompanied by the ultimate maturation of myofibers. Myostellite cells, with multipotency, can differentiate to muscle cells, but are not able to form the myofibers. During postpartum growth, these cells act as the source of new myonuclei which play a major role in fiber size and regeneration process. Despite this contribution, myonuclei remain mitotically dormant. The number of fibers is determined during the prenatal development stage in most of the mammalian species and remain fixed throughout life. Albeit, under the influence of the genetic and physiological factors, the size of the fibers increases without an increase in the number of fibers [29]. During postpartum muscular development, if the fiber numbers are more, then the individual fiber grows slowly and vice versa [29]. In an adult, the muscle's cross-sectional area directly relates to the number and size of fibers. One such example is of massive loin area which is composed of, in most cases, the low fiber size and high fiber number and vice-versa. However, the best loin area can be achieved through an optimal combination of fiber size and fiber number.

\section{MOLECULAR MECHANISMS OF MYOGENESIS AND INDICATORS OF MEAT QUALITY}

In the late 1980s, the revolutionary discovery of the myoblast differentiation $(M y o D)$ family of basic-helix-loop-helix transcription factors responsible for regulating the molecular mechanism of muscle development has opened a new arena of discussion. The four master members of the $M y o D$ family, myogenic regulatory factors (MRFs), MRF4, myogenin $(M y o G)$, and myogenic factor 5, play key roles in myogenesis. Regarding their origin, different parts of the muscles have different origins. For example, trunk and limb muscles are engendered from somite-derived dermomyotome. While extraocular, neck, and head muscles originate from cranial mesoderm [30]. During myogenesis, microsatellite cells pass through several processes regulated by vital transcriptional factors giving rise to myoblast cells which, ultimately, differentiates to form myofibers [31]. From the surrounding environment, extracellular signaling molecules released are bone morphogenetic protein (BMPs), wingless and Int (Wnts), and sonic hedgehog (Shh) responsible for sclerotome differentiation and determination [32]. Transcription factors produced from these signaling proteins affect stem cells responsible for the determination of the myogenic fate. These signaling molecules are released from different parts, but all have effects on sclerotome development. BMP and the Shh are released from the notochord through transcription factor paired box protein (Pax1), which plays a significant role in sclerotome development. Paxl is responsible for the changes in sclerotome progenitor cell's epithelium, which ultimately differentiate into chondrocytes. Wnt 1 and Wnt $3 a$ determine the myogenic fate of epaxial dermomyotome, both of which are secreted along with Shh. Shh is secreted from the floor plate of the neural tube and the notochord, while Wnt 1 and $W n t 3 a$ are released from the dorsal neural tube. Wnt7a is 
responsible for specifying the myogenic fate of hypaxial dermomyotome which is released from the dorsal ectoderm [33].

The quality of meat mainly depends on the type of myofibers. A myofiber is divided into four types due to the presence of the phenomenon of polymorphism in the myosin heavy chain. The type is I with myosin heavy chain $(\mathrm{MyHC}) \mathrm{I}$, type IIa with $M y H C$ IIa, type IIx with $M y H C$ IIx, and type IIb with $M y H C I I b$ [34]. The type I and IIa fibers are included in slow and fast oxidative muscle types, while type IIx and IIb fibers are considered intermediate and fast glycolytic myofibers. If we compare the properties of both fiber types, then we can conclude that type I and type II have higher myoglobin content, more mitochondria, low glycolytic capacity, and less myosin ATPase activity. The type IIb fibers have more glycogen, longer fiber size, and they show quick contractions. The pork flavor, tenderness, water holding capacity, and IMF are determined by type I and II type fibers, and these fibers also reduce the risk of soft, exudative, and pale pork efficiently $[35,36]$.

\section{MicroRNAs AND THEIR ROLE IN MYOGENESIS}

\section{Overview of miRNAs}

MicroRNAs are short (approximately 22 to 25 nucleotides), non-coding, single-stranded RNA molecules that are responsible for controlling gene expression through translational degradation, repression, and deadenylation of target mRNA. The degradation of the target mRNA to terminate protein translation is achieved through the binding of miRNA with RNA-induced silencing complex (RISC) at the 3'untranslated region ( $3^{\prime}$ UTR) [37]. These small non-coding RNAs play significant roles in different biological processes, with inevitable roles during adipogenesis [38] and myogenesis [39]. RNA polymerase II plays a major role in the transcription of miRNA into pri-miRNAs [40]. Then pri-miRNA is wrapped into a hairpin structure and further processed by a nuclear endonuclease RNAIII, Drosha, which on an average adds 70 to 90 nucleotide precursors and forms the pre-miRNAs [41]. After that, pre-miRNA transfers to the cytoplasm at the place where Dicer is present which belongs to the RNase III endonuclease, this is also responsible for the conversion of the pre-miRNA into mature miRNA [42]. Before the degradation of mature miRNA, miRNA combines with Argonaute protein and forms the RISCs. After the RISCs formation, mature miRNAs are degraded [43]. The activity of the RISCs is the same as that of exonuclease and endonuclease. RISC plays a crucial role in both translation and stability of mRNA [44]. Studies suggest that the earliest miRNA discovered in Caenorhabditis elegans gene having 22nt [45] was named as let-7 comprised of 22nt [46]. With time, thousands of miRNAs were recognized in different species. According to the miRbase, 21.0 total 28,645
miRNA were estimated (http://www.mirbase.org/). In different species, different kinds of miRNA prophesied and confirmed. The total number of miRNA present in humans is 2,588 [47], in mice is 1,915 [48], in bovine is 793 [49] and in sheep, the number of respective miRNAs is just 153 [50,51].

\section{Role of miRNAs in myogenesis}

The miRNAs play significant roles in the physiological processes including proliferation, apoptosis, and differentiation and all of these steps have a direct influence on embryogenesis, development timing, organogenesis, growth control, and cell linage [52]. miRNAs play significant roles in myogenesis which involves different steps including muscle cell proliferation and differentiation, determination of myofibers, and skeletal muscle atrophy or hypertrophy. During normal muscle growth, miRNA, and the gene coding for proteins interlinking with each other show the Spatio-temporal expression patterns [53]. Previous studies reported that miRNAs play major roles in porcine myogenesis [23,54-56].

Skeletal muscles play significant roles in energy metabolism, exercise [57], and are the main component of meat. Based on weight, skeletal muscles occupy a total of $40 \%$ of body mass. The composition of skeletal tissue is heterogeneous and comprised of different kinds of fibers. These fibers are generally divided into three categories, glycolytic (white fibers), oxidative (red fibers), and oxidative-glycolytic (intermediate fibers). The division of fibers is based on various kinds of $M y H C$. White fibers have $M Y H 1$, red fibers have $M Y H 7$, and intermediate fibers have $\mathrm{MYH} 2[35,58]$. In a comparative scenario of red and white fibers, red fibers have more myoglobin, lipids, capillaries, and mitochondria as compared to white fibers. While the white fibers have a higher level of lactate dehydrogenase $\mathrm{A}$, which is the master glycolytic enzyme in skeletal muscles [56].

With the advancement in knowledge, it is suggested that glycolytic and oxidative skeletal muscles have the same miRNA expression during different stages of development due to their metabolic requirements $[59,60]$. Recently, Chen et al. analyzed the expression of miRNAs in the longissimus dorsi of Chinese native Rongchang pigs at weaning and slaughter time. They found 19 novel and 186 previously known miRNAs related to the skeletal muscle development in the Rongchang pig. Porcine miR-27, miR-299, and miR432-5p showed downregulated expression patterns in adult pigs. While in weaning pigs, miR-7134-3p and 664-5p were significantly upregulated. These miRNAs which playing significant roles in skeletal muscle development could be used as biomarkers after further validation. Further, the authors also reported that miR217 could act as an inhibitor of porcine satellite cells (PSCs) proliferation and differentiation through downregulating the expression of $c y c l i n B$, cyclin $D$, as well as proliferating cell nuclear antigen (PCNA) and $M y o G$ and $M y H C$ respec- 
tively [61]. Remarkably, miR-208b and miR-499 are responsible for the transcriptional repression of the slow-twitch protein gene $S R Y$-box transcription factor 6 (Sox6). So, both of these miRNAs are directly linked with the oxidative red fibers [62]. However, porcine miR-208b also regulates the expression of Sox6 and MYH7 which effects the myofibers characteristics and pork quality [63]. For the differentiation event to take place, the arrest of the cell cycle and a decrease in DNA synthesis is critical [25]. In muscle cell differentiation, miR206 plays its role in multiple ways, one being the inhibition of DNA polymerase alpha 1 (Pola1) which is the largest DNA polymerase subunit and controller of DNA synthesis. Inhibition of Polal leads to the cell cycle dormancy and starting of the differentiation of myoblasts in C2C12 cells [25]. Another mechanism through which miR-206 regulates the differentiation of skeletal muscle cells is the inhibition of Pax3 and Pax7 at particular timespan in development for promoting the terminal differentiation of myoblasts [64]. Both Pax3 and $P a x 7$ are involved in cell survival and maintenance of myoblast and satellite cell proliferation $[65,66]$. Thus, the timely inhibition of these factors is necessary to start the differentiation of myoblasts which is achieved by the higher expression of miR-206 during embryonic development [64]. Further, the binding of myogenic factors, $M y o D$ and $M y o G$, to the upstream regions of miR-206 and miR-133b, was evidenced through chromatin immunoprecipitation [67]. In addition to the above-mentioned mechanisms, miR-206 involves the enhancement of muscle cell differentiation by stopping the activity of the connexin 43 (Cx43) gene responsible for muscle cell fusion [68]. Another study reported the combined effect of miR-1/206 in the regulation of porcine skeletal muscle development. The secreted frizzled-related protein 1 (SFRP1), inhibitor of Wnt signalling pathway, was found to be regulated by the miR-1/206 in porcine iliac endothelial cells [69].

Another important myomiR to play a similar kind of role like miR-206 is miR-1. Both miR-1 and miR-206 have the same seed sequence and target genes (Cx43, Pax3, and Pax7). But the miR-1 has more target genes and thus, plays more regulatory roles in skeletal muscle differentiation as compared to miR-206. miR-1 binds to the 3'UTR of class II histone deacetylase, histone deacetylase 4 (HDAC4) mRNA which inhibits the myocyte enhancer factor-2 (MEF2) protein expression required for enhancement of muscle development $[20,70]$. Additionally, miR-1 also inhibits the expression of ying-yang 1 (YY1), which plays a negative role in muscle gene transcription [71]. More advanced studies reported that miR-1 and miR-206 both are closely related miRNAs to play key roles in myogenesis in mouse myoblast cell line, $\mathrm{C} 2 \mathrm{C} 12$. Several genes including SWI/SNF-related matrix-associated actindependent regulator of chromatin subfamily B member 1, 2, mitogen-activated protein kinase kinase kinase kinase 3 , ho- meobox protein MOX-2, and frizzled-7 have a direct effect on miR-1 and miR-206 which triggers skeletal muscle development [72]. Further, miR-1 was also found to target the calponin 3 (CNN3) gene which is involved in skeletal muscle development in pigs [73]. Hong et al [74] reported two SNPs at the miR-1 locus in Berkshire, Landrace, and Yorkshire pigs. These SNPs were related to the type I and type IIa myofibers area and composition and caused the alteration in levels of miR-1 which is associated with regulating myofibers type determination [74].

Another myomiR to play significant roles in skeletal muscle development is miR-133. This miRNA occurs in two forms, miR-133a and miR-133b. Transcription factors like $M y o D$, $M y o G$, serum response factor, and MEF2 act as the regulators of miR-1 and miR-133a [20]. miR-133 also shows the muscle-specific expression-pattern and regulates the expression of mastermind-like protein 1 , insulin-like growth factor 1 receptor, and neural polypyrimidine tract binding protein for the differentiation of skeletal muscles. Metabolic properties associated with fiber type impact the conversion of muscles to meat and eventually to meat quality. Other miRNAs involved in porcine skeletal muscle development include miRNA-21, a novel myogenic miRNA that regulates skeletal muscle development through controlling the Pphosphatidylinositol-3-kinase/protein kinase $\mathrm{B} /$ mammalian target of rapamycin (PI3K/Akt/mTOR) signaling by targeting the transforming growth factor- $\beta$ I (TGF $\beta I)$ gene [18]. In PSCs in skeletal muscle miR-22 inhibits the proliferation through targeting the cyclin $D 1$, cyclin $B 1$, and $p 21$ but promotes the differentiation through regulating the expression of $M y o G$ and $M y H C$ [61]. Further, miR-27a inhibits the expression of $M y o G$ and it also regulates the protein kinase $\mathrm{B} /$ forkhead box protein $\mathrm{O} 1(\mathrm{Akt} / \mathrm{FoxO})$ signal pathway during porcine myogenesis [75] while miR27b acts to promote PSCs myogenesis by targeting $M y o D$ family inhibitor (MDFI) [76]. Besides, mi-34c, inhibits PSCs proliferation and promotes PSCs differentiation. miR-34c forms a regulatory loop with Notch1 for repressing muscle development through inhibiting the proliferation of PSCs [77], ssc-miR-143-3p regulates the expression $M Y H 7$ in skeletal muscle PSCs through the HDAC4-MEF2 pathway for regulating myofibers differentiation in skeletal muscles [78], miR-155 acts through the regulation of olfactomedin-like protein 3 (OLFML3) for playing its major role in swine prenatal myogenesis [79], miR-199b regulates the porcine skeletal muscle satellite cell's proliferation through a feedback loop with the JAG1-Notch1 signal pathway [80], miR-378 acts through regulation of mitogen-activated protein kinase 1 (MAPK1), and bone morphogenetic protein 2 (BMP2) is responsible for porcine myogenesis [12]. Ren et al [81] analyzed the expression of miR-432 in skeletal muscles of embryonic and adult Landrace pigs. The expression of miR-432 was found to be higher in 
Table 1. Different miRNAs and their roles in porcine skeletal muscle development

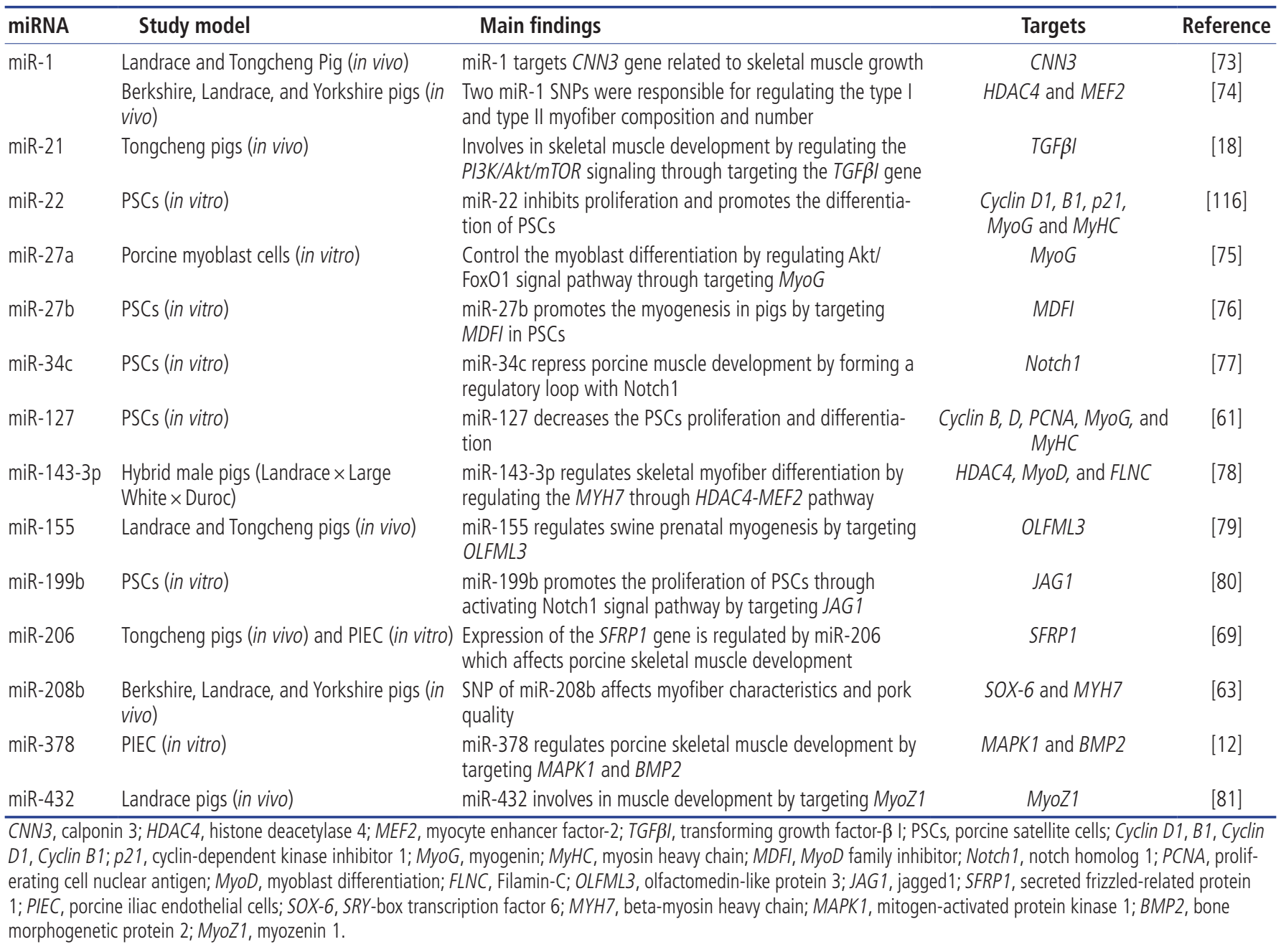

embryonic samples as compared to the samples from adult stages. Myozenin1 (MYOZ1) protein involved in the muscular sarcomere microstructure was targeted by miR-432, thus, helping in the myogenesis along with other myomiRs [81]. The summary of these miRNAs and their roles in porcine myogenesis along with their target genes is given in Table 1.

\section{ROLE OF miRNAs IN PORK QUALITY}

miRNAs and the development of meat fiber

Meat quality depends upon the meat composition comprised of the myofibers (lean to fat ratio) and other palatability factors such as its visual look, smell, juiciness, tenderness, and flavor. The most significant factor that affects meat quality is the type of fibers [82]. The myofibers are categorized into four groups based on MyHC polymorphisms. Myofibers comprised of type I having $M y H C$ I, type IIa having $M y H C$ II, type IIx having MyHC IIx, and type IIb having MyHC IIb [34]. Type I and type IIa fibers are fast oxidative or slow myofibers while type IIx and type IIb are fast glycolytic and intermediate myofibers. When we compare the property of type IIb with type I fibers it is noted that type I has more myoglobin and mitochondria content, low glycolytic capacity, myosin ATPase activity level. In contrast to that, type IIb fibers are enriched with more glycogen, and longer fiber size, so, they show a more rapid contraction speed. The fiber type I and type II are responsible for tenderness, flavor, water holding capacity and IMF of meat and also play a significant role in decreasing the production of exudative, pale and soft pork $[35,83]$.

Transcription factors play a significant role in the determination of myofiber types. Sox6 is an important transcriptional factor belonging to Sox (Sry-related high mobility group [HMG] box) family, which is extensively present in skeletal and cardiac muscles [84]. Sox6 was first isolated from an adult mouse testis [85]. It plays significant roles in embryonic myogenesis and also responsible for the maintenance of mature myofibers $[84,86]$. The absence of Sox6 causes a reduction in the differentiation of myofibers which makes it obvious that Sox6 plays a crucial role in the formation of myogenic 
fibers [86].

The other members of the myomiRs include miR-208a, miR-208b, and miR-499-5p. These three myomiRs are highly homogenous and all exhibit myofibers identification and are responsible for the switching of myosin [87]. They play roles in the determination of myofibers and also hold the ability to regulate myosin switching. Fast skeletal muscle genes, Troponin T3 (Tnnt3), and Troponin i2 (Tnni2) were expressed in the heart upon the deletion of miR-208a [88]. Further, the deletion of miR-208b and miR-499-5p prompted the loss of type I myofiber [89]. In PSCs, the overexpression of miR-499-5p resulted in increased expression of $\mathrm{MyHCI}$ and $\mathrm{MyHC}$ IIa mRNA. This shows the importance of miR499-5p in myofiber specification in pigs [90]. The advanced research in the field of molecular mechanisms regulating the development and transition of myofibers has explored the roles of miRNAs in these mechanisms. One such example includes the role of miR-499-5p in soleus and extensor digiorum longus myofibers determination of swine through regulation of Sox6. The miR-499-5p through downregulation of Sox 6 causes oxidative myofibers formation. This mechanism introduces a new theme in the betterment in pig meat quality, flavor, tenderness, and IMF.

Type IV collagen encodes from the collagen, type III, alpha 1 (COL3A1) gene [91]. Collagen IV is a master component of various tissues [92] and plays a significant role in smooth muscle integrity and tension conservation [93]. Intramuscular (IM) collagen plays a major role in meat quality including water holding capacity and tenderness [94]. The newly stated conserved miRNA-29 family acts as a master regulator in extracellular matrix homeostasis [95]. The miRNA-29 family includes miR-29a, miR-29b, miR-29c, and miR-29d. The miR29 family has major roles in regulating extracellular matrix genes including collagen, so, it is responsible for the fibrosis of many organs [96]. In muscle, COL3A1 has a great influence on intramuscular collagen content and characteristics [97]. In Laiwu pigs, higher expression of COL3A1 produces more type IV collagen due to which its meat has a high waterholding capacity and good tenderness capacity [97].

\section{INTERLINKING OF miRNAs AND IMF IN THE CONTEXT OF PORK QUALITY}

China is the biggest producer and consumer of pork. Pork consumers tend to consume pork with good IMF which is also a key indicator of pork quality $[98,99]$. The contents of IMF are used as a trait for quantifying the percentage of fat content in myofibers and it acts as an economic factor in the pork industry. It impacts the overall carcass quality not only through marbling appearance but also through affecting the tenderness and juiciness of meat [100]. Thus, the researchers are showing great interest to produce pork with high IMF contents. Thus far, the molecular mechanisms underlying the deposition of IMF are not clear. In recent years, some progress has been made in exploring the role of miRNAs in intramuscular preadipocyte development [101]. IMF deposition is a complex process that could be diverse among different species, breeds, age, and depends upon the nutrition [102-104]. The IMF content may vary from $2 \%$ to $10 \%$ in different breeds of swine [105]. But the understanding of the genetic and molecular players in IMF deposition could help in the selection and breeding of high IMF content animals. Therefore, in recent years, researchers have scratched the surface of this field for understanding the molecular mechanisms governing IMF deposition, but much more work is needed to establish the paradigm-shifting impact in improving the quality of pork production.

The expression of miRNAs was analyzed by Liu et al [99] in the longissimus dorsi muscle of Yorkshire (YY, lean-type) and Chinese Wannanhua (WH, fatty) pigs. They found 598 miRNAs from which 42 were differentially expressed between YY and WH pigs. Two miRNAs, miR-196a/b (miR-196a, miR-196b-5p), were highly expressed in WH pigs giving the clue about their influence in porcine adipogenesis an adipocytokine signaling pathways [99]. The differential expression of miRNAs between IM and subcutaneous (SC) adipocytes from Jiaxing black pigs, one of the Taihu pig breeds well known for its high IMF and excellent pork flavor [106], showed 155 miRNAs with significant differential expression (SDE). Target genes of SDE miRNAs were enriched in categories and pathways related to fatty acid biosynthesis, transcriptional regulation, and MAPK as well as PI3K-Akt pathways. The expression of miR-206 was 36- fold higher in IM adipocytes as compared to those of SC adipocytes. The role of miR-206 is to regulate adipocyte proliferation through star-related lipid transfer domain containing 7 (STARD7) and it represses kruppel-like factor 4 (KLF4) expression which results in inhibition of adipogenesis. Thus, miR-206 acts as a suppressor of adipogenesis, and its attenuation can help in the production of pork with higher IMF [107]. Recently, Sun et al [108] analyzed the miRNA sequencing of high $(2.94 \%$ $\pm 0.04 \%)$ and low $(1.62 \% \pm 0.02 \%)$ IMF group samples from Yorkshire pigs. From a total of 268 identified miRNAs, 28 were differentially expressed between two groups. From these 28 differentially expressed miRNAs, 13 were upregulated and 15 were downregulated. Top five differentially expressed miRNAs included miR-365-3p, miR-208b, miR-206, miR126-5p, and miR-10a-5p, from which only miR-365-3p was highly expressed in low IMF group while others were high in high IMF group. Additionally, the authors reported that hsa-miR-208a-3p only expressed in the high IMF group, whereas has-miR-500a-5p was found only in the low IMF group [108].

Moreover, miR-34a targets the 3'UTR of Acyl-CoA synthe- 
Table 2. Different miRNAs involved in intramuscular fat deposition in porcine skeletal muscles

\begin{tabular}{|c|c|c|c|c|}
\hline miRNA & Study model & Main findings & Targets & Reference \\
\hline \multirow[t]{2}{*}{ miR-34a } & $\begin{array}{l}\text { Porcine primary IM preadipocytes (in } \\
\text { vitro) }\end{array}$ & $\begin{array}{l}\text { This miRNA acts as a regulator of IMF deposition } \\
\text { in pigs }\end{array}$ & $\begin{array}{l}\text { ACSL4, PPAR } \gamma, a P 2 \text {, and } \\
\text { SREBP-1C }\end{array}$ & [109] \\
\hline & Porcine IM preadipocytes (In vitro) & $\begin{array}{l}\text { miR-34a regulates IMF deposition through target- } \\
\text { ing PDGFR gene }\end{array}$ & PDGFR $\alpha, P P A R g$, and FABP4 & [110] \\
\hline miR-125-5p & Porcine IM preadipocytes (in vitro) & $\begin{array}{l}\text { This miRNA acts as a novel regulator for IMF } \\
\text { deposition through regulating the proliferation } \\
\text { and differentiation of porcine IM preadipocytes }\end{array}$ & KLF13 and ELOVL6 & {$[101]$} \\
\hline miR-146a-5p & Porcine IM preadipocytes & $\begin{array}{l}\text { miR-146a-5p regulates the IMF deposition } \\
\text { through controlling the proliferation and differen- } \\
\text { tiation of porcine IM preadipocytes }\end{array}$ & SMAD4 and TRAF6 & [111] \\
\hline miR-206 & $\begin{array}{l}\text { Porcine IM and SC adipocytes (in } \\
\text { vitro) }\end{array}$ & $\begin{array}{l}\text { miR-206 suppresses the adipogenesis in porcine } \\
\text { IM and SC adipocytes }\end{array}$ & KLF4 and STARD7 & {$[107]$} \\
\hline miR-425-5p & Porcine IM preadipocytes (in vitro) & $\begin{array}{l}\text { miR- } 425-5 p \text { regulates the proliferation and adipo- } \\
\text { genic differentiation of IM preadipocytes }\end{array}$ & $\begin{array}{l}\text { PPAR } \gamma, F A B P 4, F A S N \\
\text { Cyclin } B, E \text {, and } K L F 13\end{array}$ & {$[115]$} \\
\hline
\end{tabular}

IM, intramuscular; IMF, intermuscular fat; $A C S L 4$, acyl-CoA synthetase long-chain family member 4; PPAR protein 2; SREBP-1C, sterol regulatory element-binding protein; PDGFR $\alpha$, platelet-derived growth factor receptor; PPARg, peroxisome proliferator-activated receptor gamma; FABP4, fatty acid-binding protein; KLF13, kruppel like factor 13; ELOVL6, ELOVL fatty acid elongase 6; SMAD4, SMAD family member 4; TRAF6, TNF receptor-associated factor 6; SC, subcutaneous.

tase long-chain family member 4 (ACSL4). Pig preadipocytes show the expression of ACSL4 throughout the differentiation process. The transfection of miR-34a mimic tends to reduce the lipid droplet synthesis during adipogenesis while miR34a inhibition increases the chances of lipid droplet formation. The expression miR34a target genes which included genes related to lipogeneses such as ACSL4, peroxisome proliferator-activated receptor $\gamma(P P A R \gamma)$, adipocyte protein $2(a P 2)$, and sterol regulatory element-binding protein-1C (SREBP-1C) was reduced upon overexpression of miR-34a while, downregulation of miR-34a had opposite results [109]. In addition to this mechanism for regulating the adipogenesis, miR-34a also inhibits the adipogenesis activity of platelet-derived growth factor receptor A (PDGFR $\alpha$ ), a positive regulator of adipogenesis and IMF deposition in pigs, and controls the expression of lipogenesis genes PPARg and fatty acid binding protein 4 (FABP4) [110]. The miR-125-5p was found to regulate the proliferation and differentiation of porcine intramuscular preadipocytes. The overexpression of miR-125$5 p$ in porcine preadipocytes enhanced the proliferation and reduced the differentiation of porcine IM preadipocytes while the downregulation of miR-125-5p showed opposite results. This effect was due to the targeting of porcine KLF13 and ELOVL fatty acid elongase 6 (ELOVL6), a regulator of fatty acid composition, through miR-125-5p [101]. Further, miR-146a$5 p$ acts as a potential regulator of porcine IMF adipogenesis. The mimics of miR-146a-5p tend to inhibit the proliferation and differentiation of porcine IM preadipocytes while miR146a-5p inhibitors augment the cell proliferation differentiation of preadipocytes. The proposed mechanism for regulation of preadipocyte proliferation by miR146a-5p is through targeting of SMAD family member 4 which diminishes TGF- $\beta$ signaling. While the differentiation of adipocytes controlled through targeting tumor necrosis factor (TNF) receptor-associated factor 6 (TRAF6) attenuates the nuclear factor kappa beta $(N F-\kappa B)$ signaling. This miRNA could also be considered as a biomarker for amending the IM adipogenesis to improve pork quality [111]. The overexpression of miR-181a promoted the accumulation of lipid droplets, raised the amount of triglycerides, and decreased the TNF- $\alpha$ protein expression in porcine preadipocytes, while the inhibition of this miRNA showed opposite effects [112]. Another recent study reported that miR-181a promotes the differentiation of porcine preadipocytes by targeting TGF $\beta R 1$ [113]. In addition, the expression of miR-185 was found to gradually increase during 3T3-L1 cell differentiation. The overexpression of miR-185 led to the suppression of adipogenic markers, PPAR $\gamma, F A B P 4$, fatty acid synthase (FAS), and lipoprotein lipase $(L P L)$, and reduced the lipid accumulation in 3T3-L1 cells. while the inhibition of miR-185 promoted the differentiation of 3T3-L1 cells. This effect was due to the targeting of the SREBP-1 gene by miR-185 [114]. Another miRNA, miR-425-5p also regulates the adipogenic differentiation of IM preadipocytes. The overexpression of miR-425$5 \mathrm{p}$ inhibits the IM adipogenic differentiation along with the downregulation of adipogenic marker genes PPAR $\gamma, F A B P 4$, and fatty acid synthase. While the inhibitors of miR-425-5p augments adipogenesis. The inhibitory effect of miR425-5p on IM preadipocyte proliferation and adipogenesis is through repression of cyclin $B$ and KLF13 respectively [115]. These findings are in addition to the list of miRNAs for regulating the lipogenesis and ultimately the IMF deposition in skeletal muscles of pig. The summary of roles of aforementioned miRNAs in IMF in porcine skeletal muscles is given in Table 2. 


\section{CONCLUSION AND PROSPECTS}

Myogenesis in farm animals is directly linked to the production of meat and its overall quality. To date, the molecular mechanisms involved in governing the muscle development and deposition of fat in muscles to increase the quality of meat produced are not much understood. In recent years, miRNAs were found to play important roles in regulating the expression of some important genes and transcription factors involved in muscle development and IMF deposition in pigs. miRNAs could have significant influences on muscle traits, and play key roles in the phenotypic variation of the porcine muscle. However, underlying genetic factors and functional validation of each miRNA-target relationship remain to be determined. Thus, understanding the molecular mechanisms of myogenesis can turn out to be the breakthrough for increased meat production for meeting global food demands.

\section{CONFLICT OF INTEREST}

We certify that there is no conflict of interest with any financial organization regarding the material discussed in the manuscript.

\section{ACKNOWLEDGMENTS}

This work was supported by the National Natural Science Foundation of China (No.31772562), The youth Project of Innovative Strong School Engineering by the Department of Education of Guangdong Province (2019KQNCX042), and the Key Platform Project of Innovative Strong School Engineering by the Department of Education of Guangdong Province (2018302).

\section{REFERENCES}

1. United Nations. World Population Prospects 2019. New York, USA: United Nations; 2019.

2. Picard B, Berri C, Lefaucheur L, Molette C, Sayd T, Terlouw C. Skeletal muscle proteomics in livestock production. Brief Funct Genomics 2010;9:259-78. https://doi.org/10.1093/bfgp/ elq005

3. Picard B, Lefaucheur L, Berri C, Duclos MJ. Muscle fibre ontogenesis in farm animal species. Reprod Nutr Dev 2002; 42:415-31. https://doi.org/10.1051/rnd:2002035

4. Karlsson AH, Klont RE, Fernandez X. Skeletal muscle fibres as factors for pork quality. Livest Prod Sci 1999;60:255-69. https://doi.org/10.1016/S0301-6226(99)00098-6

5. Merks JWM. One century of genetic changes in pigs and the future needs. BSAP Occas Publ 2000;27:8-19. https://doi.org/ $10.1017 /$ S1463981500040498
6. Latorre MA, Pomar C, Faucitano L, Gariépy C, Méthot S. The relationship within and between production performance and meat quality characteristics in pigs from three different genetic lines. Livest Sci 2008;115:258-67. https://doi.org/10. 1016/j.livsci.2007.08.013

7. Newcom DW, Stalder KJ, Baas TJ, Goodwin RN, Parrish FC, Wiegand BR. Breed differences and genetic parameters of myoglobin concentration in porcine longissimus muscle. J Anim Sci 2004;82:2264-8. https://doi.org/10.2527/2004.828 2264x

8. Ryu YC, Choi YM, Lee SH, et al. Comparing the histochemical characteristics and meat quality traits of different pig breeds. Meat Sci 2008;80:363-9. https://doi.org/10.1016/j.meatsci. 2007.12.020

9. Zhou B, Liu HL, Shi FX, Wang JY. MicroRNA expression profiles of porcine skeletal muscle. Anim Genet 2010;41:499508. https://doi.org/10.1111/j.1365-2052.2010.02026.x

10. Siengdee P, Trakooljul N, Murani E, et al. Pre- and post-natal muscle microRNA expression prof les of two pig breeds differing in muscularity. Gene 2015;561:190-8. https://doi.org/ 10.1016/j.gene.2015.02.035

11. Redshaw Z, Sweetman D, Loughna PT. The effects of age upon the expression of three miRNAs in muscle stem cells isolated from two different porcine skeletal muscles. Differentiation 2014;88:117-23. https://doi.org/10.1016/j.diff.2014. 12.001

12. Hou X, Tang Z, Liu H, Wang N, Ju H, Li K. Discovery of microRNAs associated with myogenesis by deep sequencing of serial developmental skeletal muscles in pigs. PLoS One 2012;7:e52123. https://doi.org/10.1371/journal.pone.0052123

13. Tang Z, Yang Y, Wang Z, Zhao S, Mu Y, Li K. Integrated analysis of miRNA and mRNA paired expression profiling of prenatal skeletal muscle development in three genotype pigs. Sci Rep 2015;5:15544. https://doi.org/10.1038/srep15544

14. Mai M, Jin L, Tian S, et al. Deciphering the microRNA transcriptome of skeletal muscle during porcine development. Peer J 2016;4:e1504. https://doi.org/10.7717/peerj.1504

15. Nielsen M, Hansen JH, Hedegaard J, et al. MicroRNA identity and abundance in porcine skeletal muscles determined by deep sequencing. Anim Genet 2010;41:159-68. https://doi. org/10.1111/j.1365-2052.2009.01981.x

16. Liu X, Trakooljul N, Hadlich F, Muráni E, Wimmers K, Ponsuksili S. MicroRNA-mRNA regulatory networking fine-tunes the porcine muscle fiber type, muscular mitochondrial respiratory and metabolic enzyme activities. BMC Genomics 2016;17:531. https://doi.org/10.1186/s12864-016-2850-8

17. Sang I, Jung C, Hye K, Seo Y, Hwan D. Cloning and characterization of microRNAs from porcine skeletal muscle and adipose tissue. Mol Biol Rep 2010;37:3567-74. https://doi. org/10.1007/s11033-010-0005-6

18. Bai L, Liang R, Yang Y, et al. MicroRNA-21 Regulates PI3K/ Akt/mTOR signaling by targeting TGF $\beta$ I during skeletal 
muscle development in pigs. PLoS One 2015;10:e0119396. https://doi.org/10.1371/journal.pone.0119396

19. McCarthy JJ, Esser KA. MicroRNA-1 and microRNA-133a expression are decreased during skeletal muscle hypertrophy. J Appl Physiol 2007;102:306-13. https://doi.org/10.1152/jappl physiol.00932.2006

20. Chen JF, Mandel EM, Thomson JM, et al. The role of microRNA-1 and microRNA-133 in skeletal muscle proliferation and differentiation. Nat Genet 2006;38:228-33. https://doi. org/10.1038/ng1725

21. Xie SS, Huang TH, Shen Y, et al. Identification and characterization of microRNAs from porcine skeletal muscle. Anim Genet 2010;41:179-90. https://doi.org/10.1111/j.1365-2052. 2009.01991.x

22. Rosenberg MI, Georges SA, Asawachaicharn A, Analau E, Tapscott SJ. MyoD inhibits Fstll and Utrn expression by inducing transcription of miR-206. J Cell Biol 2006;175:7785. https://doi.org/10.1083/jcb.200603039

23. Huang TH, Zhu MJ, Li XY, Zhao SH. Discovery of porcine microRNAs and profiling from skeletal muscle tissues during development. PLoS One 2008;3:e3225. https://doi.org/10. 1371/journal.pone.0003225

24. McDaneld GT, Smith TPL, Doumit ME, et al. MicroRNA transcriptome profiles during swine skeletal muscle development. BMC Genomics 2009;10:77. https://doi.org/10.1186/ 1471-2164-10-77

25. Kim HK, Lee YS, Sivaprasad U, Malhotra A, Dutta A. Musclespecific microRNA miR-206 promotes muscle differentiation. J Cell Biol 2006;174:677-87. https://doi.org/10.1083/jcb.2006 03008

26. Sheng X, Wang L, Ni H, et al. Comparative analyses between skeletal muscle mirnaomes from large white and min pigs revealed microRNAs associated with postnatal muscle hypertrophy. PLoS One 2016;11:e0156780. https://doi.org/10.1371/ journal.pone. 0156780

27. Arnold H-H, Braun T. 4 Genetics of muscle determination and development. Anim Reprod Sci 1999;48:129-64. https:// doi.org/10.1016/S0070-2153(08)60756-5

28. Chen J, Wei W, Xiao X, Zhu M, Fan B, Zhao S. Expression analysis of miRNAs in porcine fetal skeletal muscle on days 65 and 90 of gestation. Asian-Australas J Anim Sci 2008;21: 954-60. https://doi.org/10.5713/ajas.2008.70521

29. Rehfeldt C, Fiedler I, Dietl G, Ender K. Myogenesis and postnatal skeletal muscle cell growth as influenced by selection. Livest Prod Sci 2000;66:177-88. https://doi.org/10.1016/S03016226(00)00225-6

30. Sambasivan R, Kuratani S, Tajbakhsh S. An eye on the head: the development and evolution of craniofacial muscles. Development 2011;138:2401-15. https://doi.org/10.1242/dev. 040972

31. Buckingham M, Montarras D, Relaix F, et al. Pax3 and Pax7 mark a major population of muscle progenitor cells that con- tribute to skeletal muscle formation and regeneration. In: Neuromuscular disorders. Oxford, UK: Pergamon-Elsevier Science Ltd; 2006. pp. S48-S48.

32. Bailey P, Holowacz T, Lassar AB. The origin of skeletal muscle stem cells in the embryo and the adult. Curr Opin Cell Biol 2001;13:679-89. https://doi.org/10.1016/S0955-0674(00) 00271-4

33. Endo T. Molecular mechanisms of skeletal muscle development, regeneration, and osteogenic conversion. Bone 2015; 80:2-13. https://doi.org/10.1016/j.bone.2015.02.028

34. Pette D, Staron RS. Myosin isoforms, muscle fiber types, and transitions. Microsc Res Tech 2000;50:500-9. https://doi.org/ 10.1002/1097-0029(20000915)50:6<500::AID-JEMT7>3.0. $\mathrm{CO} ; 2-7$

35. Choi YM, Kim BC. Muscle fiber characteristics, myofibrillar protein isoforms, and meat quality. Livest Sci 2009;122:10518. https://doi.org/10.1016/j.livsci.2008.08.015

36. Warner RD, Greenwood PL, Pethick DW, Ferguson DM. Genetic and environmental effects on meat quality. Meat Sci 2010;86:171-83. https://doi.org/10.1016/j.meatsci.2010.04. 042

37. Chekulaeva M, Filipowicz W. Mechanisms of miRNA-mediated post-transcriptional regulation in animal cells. Curr Opin Cell Biol 2009;21:452-60. https://doi.org/10.1016/j.ceb.2009. 04.009

38. Walden TB, Timmons JA, Keller P, Nedergaard J, Cannon B. Distinct expression of muscle-specific MicroRNAs (myomirs) in brown adipocytes. J Cell Physiol 2009;218:444-9. https:// doi.org/10.1002/jcp.21621

39. Rooij EV, Liu N, Olson EN. MicroRNAs flex their muscles. Trends Genet 2008;24:159-166. https://doi.org/10.1016/j.tig. 2008.01.007

40. Lee Y, Kim M, Han J, et al. MicroRNA genes are transcribed by RNA polymerase II. EMBO J 2004;23:4051-60. https://doi. org/10.1038/sj.emboj.7600385

41. Lee Y, Ahn C, Han J, et al. The nuclear RNase III Drosha initiates microRNA processing. Nature 2003;425:415-9. https:// doi.org/10.1038/nature01957

42. Hutvagner G, MaLachian J, Pasquinelli AE, Balint E, Tuschi T, Zamore PD. A Cellular function for the RNA-interference enzyme dicer in the maturation of the let-7 small temporal RNA. Science 2001;293:834-8. https://doi.org/10.1126/science. 1062961

43. Gregory RI, Chendrimada TP, Cooch N, Shiekhattar R. Human RISC couples microRNA biogenesis and posttranscriptional gene silencing. Cell 2005;123:631-40. https://doi.org/10.1016/ j.cell.2005.10.022

44. Du T, Zamore PD. microPrimer: The biogenesis and function of microRNA. Development 2005;132:4645-52. https:// doi.org/10.1242/dev.02070

45. Lee Rosalind C RLF, Ambrost and V. The C. elegans heterochronic gene lin-4 encodes small RNAs with antisense com- 
plementarity to lin-14. Cell 1993;75:843-54. https://doi.org/ 10.1016/0092-8674(93)90529-Y

46. Pasquinelli EA, Reinhart BJ, Slack F, et al. Conservation of the sequence and temporal expression of let-7 heterochronic regulatory RNA. Nature 2000;408:86-9. https://doi.org/10. 1038/35040556

47. Koh W, Sheng CT, Tan B, Lee QY, Kuznetsov V, et al. Analysis of deep sequencing microRNA expression profile from human embryonic stem cells derived mesenchymal stem cells reveals possible role of let-7 microRNA family in downstream targeting of hepatic nuclear factor 4 alpha. BMC Genomics 2010; 11:S6. https://doi.org/10.1186/1471-2164-11-S1-S6

48. Ahn HW, Morin RD, Zhao H, et al. MicroRNA transcriptome in the newborn mouse ovaries determined by massive parallel sequencing. Mol Hum Reprod 2010;16:463-71. https:/doi. org/10.1093/molehr/gaq017

49. Coutinho LL, Matukumalli LK, Sonstegard TS, et al. Discovery and profiling of bovine microRNAs from immune-related and embryonic tissues. Physiol Genomics 2007;29:35-43. https://doi.org/10.1152/physiolgenomics.00081.2006

50. Caiment F, Charlier C, Hadfield T, Cockett N, Georges M, e Baurain D. Assessing the effect of the CLPG mutation on the microRNA catalog of skeletal muscle using high-throughput sequencing. Genome Res 2010;20:1651-62. https://doi.org/ 10.1101/gr.108787.110

51. Galio L, Droineau S, Yeboah P, et al. MicroRNA in the ovine mammary gland during early pregnancy: Spatial and temporal expression of miR-21, miR-205, and miR-200. Physiol Genomics 2013;45:151-61. https://doi.org/10.1152/physiol genomics.00091.2012

52. Ambros V. The functions of animal microRNAs. Nature 2004; 431:350-5. https://doi.org/10.1038/nature02871

53. Williams AH, Liu N, Rooij E, Olson EN. MicroRNA control of muscle development and disease. Curr Opin Cell Biol 2009; 21:461-9. https://doi.org/10.1016/j.ceb.2009.01.029

54. Xie SS, Huang TH, Shen Y, et al. Identification and characterization of microRNAs from porcine skeletal muscle. Anim Genet 2010;41:179-90. https://doi.org/10.1111/j.1365-2052. 2009.01991.x

55. Luo W, Nie Q, Zhang X. MicroRNAs involved in skeletal muscle differentiation. J Genet Genomics 2013;40:107-16. https://doi.org/10.1016/j.jgg.2013.02.002

56. Schiaffino S, Reggiani C. Fiber types in Mammalian skeletal muscles. Physiol Rev 2011;91:1447-531. https://doi.org/10. 1152/physrev.00031.2010

57. Güller I, Russell AP. MicroRNAs in skeletal muscle: their role and regulation in development, disease and function. J Physiol 2010;588:4075-87. https://doi.org/10.1113/jphysiol.2010. 194175

58. Li Y, Xu Z, Li H, Xiong Y, Zuo B. Differential transcriptional analysis between red and white skeletal muscle of Chinese Meishan pigs. Int J Biol Sci 2010;6:350-60. https://doi.org/

\subsection{0/ijbs.6.350}

59. Liu Y, Li M, Ma J, et al. Identification of differences in microRNA transcriptomes between porcine oxidative and glycolytic skeletal muscles. BMC Mol Biol 2013;14:7. https://doi.org/ 10.1186/1471-2199-14-7

60. Muroya S, Taniguchi M, Shibata M, et al. Profiling of differentially expressed microRNA and the bioinformatic target gene analyses in bovine fast- and slow-type muscles by massively parallel sequencing. J Anim Sci 2013;91:90-103. https://doi. org/10.2527/jas.2012-5371

61. Chen X, Zhao C, Dou M, et al. Deciphering the miRNA transcriptome of Rongchang pig longissimus dorsi at weaning and slaughter time points. J Anim Physiol Anim Nutr (Berl). 2020;104:954-64. https://doi.org/10.1111/jpn.13314

62. Gan Z, Rumsey J, Hazen BC, et al. Nuclear receptor/microRNA circuitry links muscle fiber type to energy metabolism. J Clin Invest 2013;123:2564-75. https://doi.org/10.1172/JCI67652

63. Kim JM, Lim KS, Hong JS, Kang JH, Lee YS, Hong KC. A polymorphism in the porcine $m i R-208 b$ is associated with microRNA biogenesis and expressions of SOX-6 and MYH7 with effects on muscle fibre characteristics and meat quality. Anim Genet 2015;46:73-77. https://doi.org/10.1111/age.12255

64. Chen, Jian-fu, Tao Y, Li J, Deng Z, Yan Z, et al. microRNA-1 and microRNA-206 regulate skeletal muscle satellite cell proliferation and differentiation by repressing Pax7. J Cell Biol 2010;190:867-79. https://doi.org/10.1083/jcb.200911036

65. Kassar-duchossoy L, Giacone E, Gayraud-morel B, Jory A, Gomès D, Tajbakhsh S. Pax3 / Pax7 mark a novel population of primitive myogenic cells during development. Genes Dev 2005;19:1426-31. https://doi.org/10.1101/gad.345505

66. Zammit PS, Relaix F, Nagata Y, et al. Pax7 and myogenic progression in skeletal muscle satellite cells. J Cell Sci 2006;119: 1824-32. https://doi.org/10.1242/jcs.02908

67. Rao PK, Kumar RM, Farkhondeh M, Baskerville S, Lodish HF. Myogenic factors that regulate expression of musclespecific microRNAs. Proc Natl Acad Sci USA 2006;103:87216. https://doi.org/10.1073/pnas.0602831103

68. Anderson C, Catoe H, Werner R. MIR-206 regulates connexin 43 expression during skeletal muscle development. Nucleic Acids Res 2006;34:5863-71. https://doi.org/10.1093/nar/gkl743

69. Yang Y, Sun W, Wang R, et al. Wnt antagonist, secreted frizzledrelated protein 1 , is involved in prenatal skeletal muscle development and is a target of miRNA-1/206 in pigs. BMC Mol Biol 2015;16:4. https://doi.org/10.1186/s12867-015-0035-7

70. Backs J, Worst BC, Lehmann LH, et al. Selective repression of MEF2 activity by PKA-dependent proteolysis of HDAC4. J Cell Biol 2011;195:403-15. https://doi.org/10.1083/jcb.20110 5063

71. Lu L, Zhou L, Chen EZ, et al. A novel YY1-miR-1 regulatory circuit in skeletal myogenesis revealed by genome-wide prediction of YY1-miRNA network. PLoS One 2012;7:e27596. https://doi.org/10.1371/journal.pone.0027596 
72. Goljanek-Whysall K, Pais H, Rathjen T, Sweetman D, Dalmay T, Münsterberg A. Regulation of multiple target genes by miR-1 and miR-206 is pivotal for C2C12 myoblast differentiation. J Cell Sci 2012;125:3590-600. https://doi.org/10.1242/ jcs. 101758

73. Tang Z, Liang R, Zhao S, Wang R, Huang R, Li K. CNN3 is regulated by microRNA-1 during muscle development in pigs. Int J Biol Sci 2014;10:377-85. https://doi.org/10.7150/ijbs.8015

74. Hong J, Noh S, Lee J, Kim J, Hong K, Lee YS. Effects of polymorphisms in the porcine microRNA miR-1 locus on muscle fi ber type composition and $m i R-1$ expression. Gene 2012; 506:211-6. https://doi.org/10.1016/j.gene.2012.06.050

75. Zhang S, Chen X, Huang Z, et al. Effects of MicroRNA-27a on myogenin expression and Akt/FoxO1 signal pathway during porcine myoblast differentiation. Anim Biotechnol 2018;29:183-9. https://doi.org/10.1080/10495398.2017.1348 357

76. Hou L, Xu J, Jiao Y, et al. MiR-27b promotes muscle development by inhibiting MDFI expression. Cell Physiol Biochem 2018;46:2271-83. https://doi.org/10.1159/000489595

77. Hou L, Xu J, Li H, et al. MiR-34c represses muscle development by forming a regulatory loop with Notch1. Sci Rep 2017; 7:9346. https://doi.org/10.1038/s41598-017-09688-y

78. Zuo J, Wu F, Liu Y, et al. MicroRNA transcriptome profile analysis in porcine muscle and the effect of miR-143 on the MYH7 gene and protein. PLoS One 2015;10:e0124873. https:// doi.org/10.1371/journal.pone.0124873

79. Zhao S, Zhang J, Hou X, et al. OLFML3 expression is decreased during prenatal muscle development and regulated by microRNA-155 in pigs. Int J Biol Sci 2012;8:459-69. https://doi.org/ 10.7150/ijbs.3821

80. Zhu L, Hou L, Ou J, et al. MiR-199b represses porcine muscle satellite cells proliferation by targeting. Gene 2019;691:2433. https://doi.org/10.1016/j.gene.2018.12.052

81. Ren RM, Liu H, Zhao SH, Cao JH. Targeting of miR-432 to myozenin 1 to regulate myoblast proliferation and differentiation. Genet Mol Res 2016;15:gmr15049313. http://dx.doi. org/10.4238/gmr15049313

82. Lee SH, Kim JM, Ryu YC, Ko KS. Effects of Morphological characteristics of muscle fibers on porcine growth performance and pork quality. Korean J Food Sci Anim Resour 2016;36:583-93. https://doi.org/10.5851/kosfa.2016.36.5.583

83. Lee SH, Joo ST, Ryu YC. Skeletal muscle fiber type and myofibrillar proteins in relation to meat quality. Meat Sci 2010;86: 166-70. https://doi.org/10.1016/j.meatsci.2010.04.040

84. Wen W, Chen X, Huang Z, et al. Prokaryotic expression and purification of porcine Sox6. Turk J Biol 2016;40:915-21. https:// doi.org/10.3906/biy-1507-115

85. Connor F, Wright E, Denny P, Koopman P, Ashworth A. The Sry-related HMG box-containing gene Sox6 is expressed in the adult testis and developing nervous system of the mouse. Nucleic Acids Res 1995;23:3365-72. https://doi.org/10.1093/ nar/23.17.3365

86. Quiat D, Voelker KA, Pei J, et al. Concerted regulation of myofiber-specific gene expression and muscle performance by the transcriptional repressor Sox6. Proc Natl Acad Sci USA 2011;108:10196-201. https://doi.org/10.1073/pnas.110741 3108

87. Rooij E, Quiat D, Johnson BA, et al. A family of microRNAs encoded by myosin genes governs myosin expression and muscle performance. Dev Cell 2009;17:662-73. https://doi. org/10.1016/j.devcel.2009.10.013

88. Rooij E, Sutherland LB, Qi X, Richardson JA, Hill J, Olson EN. Control of stress-dependent cardiac growth and gene expression by a microRNA. Science 2007;316:575-9. https:// doi.org/10.1126/science.1139089

89. Rooij E, Quiat D, Johnson BA, et al. Article a family of microRNAs encoded by myosin genes governs myosin expression and muscle performance. Dev Cell 2009;17:662-73. https:// doi.org/10.1016/j.devcel.2009.10.013

90. Wang XY, Chen XL, Huang ZQ, et al. MicroRNA-499-5p regulates porcine myofiber specification by controlling Sox6 expression. Animal 2017;11:2268-74. https://doi.org/:10.1017/ S1751731117001008

91. Maehata Y, Takamizawa S, Ozawa S, et al. Type III collagen is essential for growth acceleration of human osteoblastic cells by ascorbic acid 2-phosphate, a long-acting vitamin C derivative. Matrix Biol 2007;26:371-81. https://doi.org/10. 1016/j.matbio.2007.01.005

92. Bittinger F, Schepp C, Brochhausen C, et al. Remodeling of peritoneal-like structures by mesothelial cells: Its role in peritoneal healing. J Surg Res 1999;82:28-33. https://doi.org/10. 1006/jsre.1998.5449

93. Stevenson K, Kucich U, Whitbeck C, Levin RM, Howard PS. Functional changes in bladder tissue from type III collagendeficient mice. Mol Cell Biochem 2006;283:107-14. https:// doi.org/10.1007/s11010-006-2388-1

94. Yang S, Li WS, Dong F, et al. KITLG is a novel target of $m i R$ $34 c$ that is associated with the inhibition of growth and invasion in colorectal cancer cells. J Cell Mol Med 2014;18:2092102. https://doi.org/10.1111/jcmm.12368

95. Villarreal G, Oh DJ, Kang MH, Rhee DJ. Coordinated regulation of extracellular matrix synthesis by the microRNA-29 family in the trabecular meshwork. Invest Ophthalmol Vis Sci 2011;52:3391-7. https://doi.org/10.1167/iovs.10-6165

96. Wang Y, Zhang X, Li H, Yu J, Ren X. The role of miRNA-29 family in cancer. Eur J Cell Biol 2013;92:123-8. https://doi. org/10.1016/j.ejcb.2012.11.004

97. Bao X, Zeng Y, Wei S, et al. Developmental Changes of Col3a1 mRNA expression in muscle and their association with intramuscular collagen in pigs. J Genet Genomics 2007;34:2238. https://doi.org/10.1016/S1673-8527(07)60023-X

98. Scollan ND, Price EM, Morgan SA, Huws SA, Shingfield KJ. Can we improve the nutritional quality of meat? Proc Nutr 
Soc 2017;76:603-18. https://doi.org/10.1017/S0029665117 001112

99. Liu L, Qian K, Wang C. Discovery of porcine miRNA-196a/ $\mathrm{b}$ may influence porcine adipogenesis in longissimus dorsi muscle by miRNA sequencing. Anim Genet 2017;48:17581. https://doi.org/10.1111/age.12520

100. Pietruszka A, Jacyno E, Kawęcka M, Biel W. The relation between intramuscular fat level in the longissimus muscle and the quality of pig carcasses and meat. Ann Anim Sci 2015;15:1031-41. https://doi.org/10.1515/aoas-2015-0046

101. Du J, Xu Y, Zhang P, et al. MicroRNA-125a-5p affects adipocytes proliferation, differentiation and fatty acid composition of porcine intramuscular fat. Int J Mol Sci 2018;19:501. https:// doi.org/10.3390/ijms19020501

102. Katsumata M, Kobayashi H, Ashihara A, Ishida A. Effects of dietary lysine levels and lighting conditions on intramuscular fat accumulation in growing pigs. Anim Sci J 2018;89: 988-93. https://doi.org/10.1111/asj.13019

103. Madeira MS, Lopes PA, Costa P, Coelho D, Alfaia CM, Prates JAM. Reduced protein diets increase intramuscular fat of psoas major, a red muscle, in lean and fatty pig genotypes. Animal 2017;11:2094-102. https://doi.org/10.1017/S17517 31117000921

104. Chen F-F, Wang Y-Q, Tang G-R, et al. Differences between porcine longissimus thoracis and semitendinosus intramuscular fat content and the regulation of their preadipocytes during adipogenic differentiation. Meat Sci 2019;147:11626. https://doi.org/10.1016/j.meatsci.2018.09.002

105. DeVol DL, McKeith FK, Bechtel PJ, Novakofski J, Shanks $\mathrm{RD}$, Carr TR. Variation in composition and palatability traits and relationships between muscle characteristics and palatability in a random sample of pork carcasses. J Anim Sci 1988; 66:385-95. https://doi.org/10.2527/jas1988.662385x

106. Zhang W, Song Q, Wu F, et al. Evaluation of the four breeds in synthetic line of Jiaxing Black Pigs and Berkshire for meat quality traits, carcass characteristics, and flavor substances. Anim Sci J 2019;90:574-82. https://doi.org/10.1111/asj.13169 107. Xu K, Ji M, Huang X, Peng Y, Wu W, Zhang J. Differential regulatory roles of MicroRNAs in porcine intramuscular and subcutaneous adipocytes. J Agric Food Chem 2020;68:395462. https://doi.org/10.1021/acs.jafc.9b08191

108. Sun Y, Wang S, Liu H, et al. Profiling and characterization of miRNAs associated with intramuscular fat content in Yorkshire pigs. Anim Biotechnol 2020;31:256-63. https://doi.org/ 10.1080/10495398.2019.1573191

109. Wang W, Li X, Ding N, et al. miR-34a regulates adipogenesis in porcine intramuscular adipocytes by targeting ACSL4. BMC Genet 2020;21:33. https://doi.org/10.1186/s12863-020-0836-7

110. Sun Y, Qin J, Liu S, et al. PDGFR $\alpha$ regulated by miR-34a and $\mathrm{FoxO1}$ promotes adipogenesis in porcine intramuscular preadipocytes through Erk signaling pathway. Int J Mol Sci 2017;18:2424. https://doi.org/10.3390/ijms18112424

111. Zhang Q, Cai R, Tang G, Zhang W, Pang W. MiR-146a-5p targeting SMAD4 and TRAF6 inhibits adipogenensis through TGF- $\beta$ and NF- $\mathrm{KB}$ signal pathways in porcine intramuscular preadipocytes. J Anim Sci Biotechnol 2020 Jun 30 [Epub]. https://doi.org/10.21203/rs.3.rs-38947/v1

112. Li H, Chen X, Guan L, et al. MiRNA-181a regulates adipogenesis by targeting tumor necrosis factor- $\alpha$ (TNF- $\alpha$ ) in the porcine model. PLoS One 2013;8:e71568. https://doi.org/10. 1371/journal.pone.0071568

113. Zhang Z, Gao Y, Xu MQ, et al. miR-181a regulate porcine preadipocyte differentiation by targeting TGFBR1. Gene 2019; 681:45-51. https://doi.org/10.1016/j.gene.2018.09.046

114. Ning C, Li G, You L, et al. MiR-185 inhibits 3T3-L1 cell differentiation by targeting SREBP-1. Biosci Biotechnol Biochem 2017;81:1747-54. https://doi.org/10.1080/09168451.2017.13 47485

115. Chen F, Xiong Y, Peng Y, et al. miR-425-5p inhibits differentiation and proliferation in porcine intramuscular preadipocytes. Int J Mol Sci 2017;18:2101. https://doi.org/10.3390/ ijms18102101

116. Dang HQ, Xu G, Hou L, et al. MicroRNA-22 inhibits proliferation and promotes differentiation of satellite cells in porcine skeletal muscle. J Integr Agric 2020;19:225-33. https:// doi.org/10.1016/S2095-3119(19)62701-2 